\title{
Faglige retningslinjer for forebygging av selvmord i psykisk helsevern
}

Ved Fredrik A. Walby

\begin{abstract}
Suicidal atferd er nært knyttet til psykisk lidelse, og psykisk helsevern har derfor et særlig ansvar for å ha kontinuerlig fokus på selvmordsforebyggende tiltak. Samtidig er det betydelige faglige og kunnskapsmessige utfordringer på dette feltet. Nasjonale retningslinjer for forebygging av selvmord i psykisk helsevern er nå for første gang tilgjengelige i Norge, utgitt av Sosial- og helsedirektoratet* I denne artikkelen redegjøres det for bakgrunnen for de nye retningslinjene og prosessen med å utarbeide dem.
\end{abstract}

\section{Bakgrunn}

Psykisk lidelse er den faktoren som sterkest henger sammen med suicidal atferd. En lang rekke studier har funnet klare holdepunkter for psykisk lidelse ved mer enn $90 \%$ av gjennomførte selvmord i befolkningen (C avanagh et al., 2003). Tilsvaren de data kommer også fra registerstudier (Q in \& N ordentoft, 2005). I N orge er det vist økning av selvmord under behandling i psykisk helsevern i to studier ( $H$ ytten \& M ehlum, 1993; $H$ ansen et al., 2001). Fra 0 slo har vi vist at $25 \%$ av alle selvmord i perioden 1992-1997 fant sted hos personer som hadde vært innlagt til behandling i døgnavdeling mindre enn tre år før selvmordet ( $W$ al by et al., 2006). 0 gså ikke-fatal suicidal atferd utgjør et omfatten de og viktig klinisk problem; SIN TEFs kartlegging av en lang rekke akuttavdelinger viste at suicidalitet var en medvirkende faktor ved mer enn $70 \%$ av innleggelsene (Ruud et al., 2006). A ndre studier har vist om lag $50 \%$ (W al by et al., 2005; M ellesdal et al., 2005).

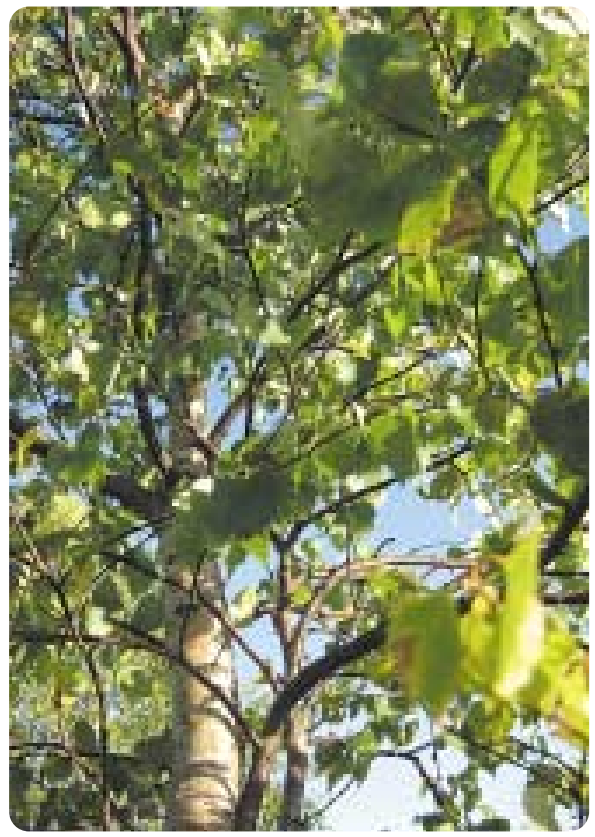

Kunnskapen om den nære sammenhengen mellom psykisk lidelse og selvmord, og føl gelig betydningen av et kontinuerlig fokus på selvmordsfare og på selvmordsforebygging i psykisk helsevern er ikke av ny dato. Imidlertid er psykisk helsevern stadig i endring; det er en økende turnover av behandlere og miljøpersonale, ansvaret for kliniske beslutninger er i betydel ig grad del egert, og moderne behandlingstilnærminger og gjeldende lovverk legger langt større vekt på pasientens sel vbestemmel sesrett i forhold til behandling. D ette, sammen med en langvarig nedbygging av sengetallet $i$ institusjonspsykiatrien bl.a. som ledd i en uttalt politisk målsetting om at helsetjenester skal gis på lavest mulige omsorgsn ivå, øker utfordringen med å sikre relevant kunnskap og kompetanse i utøvende ledd. En gjennomgang av selvmord meldt til tilsynsmyndighetene viser klart at det er et forbedringspotensial på dette området i N orge (Rønneberg \& W al by, 2008)

\section{Nasjonale retningslinjer og veiledere}

De siste 10 årene har det vært økende fokus på kvalitetsheving og kvalitetssikring av behandlingstilnærminger i helsetjenesten generelt, bl.a. som ledd i det som ofte på norsk betegnes som kunnskapsbasert praksis (Bjørndal et al., 2000; Sackett et al., 1996). Både myndigheter, pasienter og profesjonsforeninger legger stadig større vekt på at helsetjenester også for pasienter som har psykiske problemer - skal være effektive, tilgjengelige og ikke minst trygge. Sentralt i begrepet kunnskapsbasert praksis ligger det at helsetjenester skal baseres på den beste tilgjengel ige og oppdaterte forskningsbaserte kunnskap. Som et ledd i dette har man blant annet opprettet $\mathrm{N}$ asjonalt kunnskapssenter for helsetjen esten (www.kunnskapssenteret.no).

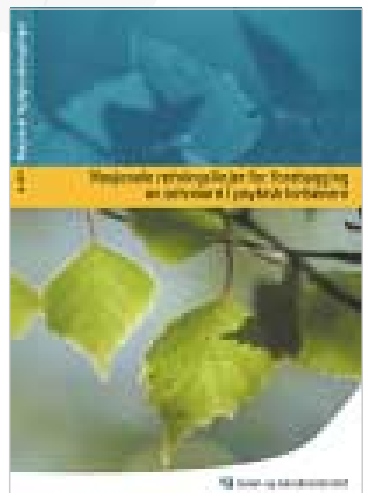

Kunnskapssenteret skal medvirke til at forskningsbasert kunnskap bidrar til gode beslutninger i helsetjenesten. D et er imidlertid helsefaglige myndigheter som har ansvaret for at de riktige beslutningene fattes, som fastsetter lover, forskrifter og fagl ige retningslinjer og som fører kontroll med hva hel setjen esten gjør.

$\mathrm{N}$ orske hel semyndigheter opererer med flere ulike nivåer av dokumenter som ledd i arbeidet med å sikre kvalitet i helsetjenesten. Det skilles mellom retningslinjer og veiledere. H elsedirektoratet definerer nasjonale retningslinjer som

"... systematisk utviklede anbefalinger, for å støtte fagpersoners og pasienters beslutninger om relevant behandling for en definert klinisk problemstilling. $\mathrm{N}$ asjonale retningslinjer fra Sosialog helsedirektoratet er utarbei det etter internasjonalt anerkjente metoder, og gir uttrykk for hva som anses som god praksis på utgivelsestidspunktet. $\mathrm{N}$ asjonale retningslinjer er i prinsippet å anse som faglige råd, og skal bygge på god, oppdatert faglig kunnskap. Retningslinjene er ment som et hjelpemiddel ved de avveininger (helse-) personellet må gjøre for å oppnå forsvarlighet og god kvalitet i tjenesten. N asjonale retningslinjer er ikke direkte bindende for mottakerne, men kan langt på vei være styrende for de valg som skal tas."

(Sosial- og helsedirektoratet, 2005).

0 gså nasjonale veiledere har samme siktemål, men er gjerne utarbeidet på en noe enklere måte. Det finnes per i dag en rekke slike retningslinjer og veiledere innenfor mange deler av helsetjenesten og flere er under utarbei delse. På det suicidologiske området har vi fra før av veilederen "Rutiner for registrering, behandling og oppfølging av pasienter innlagt i norske sykehus etter parasuicid" (Statens hel setilsyn, 2001).

* Sosial- og helsedirektoratet skiftet navn til Helsedirektoratet 1.4.08. 


\section{Utgangspunkt}

Seksjon for selvmordsforskning og -forebygging ved professor Lars M ehlum tok initiativet til utarbeidelsen av nasjonale standarder for forebygging av selvmord i psykisk helsevern i et brev til daværende Sosial- og helsedirektoratet (nå H elsedirektoratet) i 2002. D et faktiske arbeidet tok til i 2004. Det ble etablert en bredt sammen satt gruppe bestående av klinikere og forskere på feltet, ansatte ved alle de regionale sentrene (RVTS) og representanter fra profesjonsforeningene og fra brukerorganisasjoner. De første forberedende møtene ble avholdt. Som beskrevet skiller myndighetene mellom retningslinjer og såkal te veiledere. H elsedirektoratet vurderer i det enkelte tilfellet hvilken status et dokument skal få ut fra hvordan det underliggende arbeidet er utført og forhold på det aktuelle fagområdet. Imidlertid var det fra starten av arbeidet konsensus $i$ arbeidsgruppa om at dette området er så viktig at man sterkt ønsket å få til et dokument på det høyeste nivået - en nasjonal retningslinje. Dette stiller en rekke krav til hvordan arbeidsprosessen med dokumentet skal utføres for å få en tilstrekkelig systematisk og etterprøvbar struktur. Slike krav er beskrevet i detalj i et eget dokument kalt "R etningslinjer for retningslinjer "(Statens helsetilsyn, 2002). Særlig viktig er det at kunnskapsgrunnlaget som anbefalingene bygger på, er både systematisk innhentet og nøye kvalitetssikret. Det ble derfor tidlig klart at det var nødvendig å gjøre en kunnskapsoppsummering på området før utviklingsprosessen av selve retningslinjene kunne påbegynnes.

\section{Kunnskapsoppsummeringen}

En kunnskapsoppsummering er en systematisk gjennomgang av forskningen på et avgrenset felt etter på forhånd definerte kriterier for omfang av litteratursøk, metode- og kval itetskrav til primærstudier m.v. Sosial- og helsedirektoratet ga høsten $2004 \mathrm{~N}$ asjonalt kunnskapssenter for helsetjen esten i oppgave å utarbeide en slik oppsummering for selvmordsforebyggende tiltak innen psykisk helsevern. D et ble i den forbindel se nedsatt en ekspertgruppe bestående av forskere med klinisk suicido- logisk kompetanse. I tillegg bidro Kunnskapssenteret med metodekompetanse. Det ligger i kortene at slike oppsummeringer er mer krevende å gjøre jo større omfang problemstillingen har og jo mer variert litteraturen på feltet er. På dette området viste det seg raskt å bli et meget omfatten de arbeid. $M$ an valgte av den grunn å dele oppdraget $\mathrm{i}$ to deler. Del 1 besto av en systematisk oversikt over primærstudier om effekten av hhv. psykoterapi, medikamentell behandling og elektrostimulerende behandling (ECT) på selvmordsatferd (M ehlum et al., 2006). Del 2 besto av en systematisk oversikt over andre systematiske oversikter om tiltak for bedre kontinuitet i og tilgang på behandling, om tiltak for å fjerne terskler for hjelp og beskyttelsestiltak ( $M$ ehlum et al., 2007). Begge rapportene ble utført etter internasjonale standardkriterier for metodevurderinger. A rbeidet ble ferdig-

Retningslinjene er basert på en kunnskapsstatus presentert i følgende to rapporter (Mehlum et al., 2006, 2007):

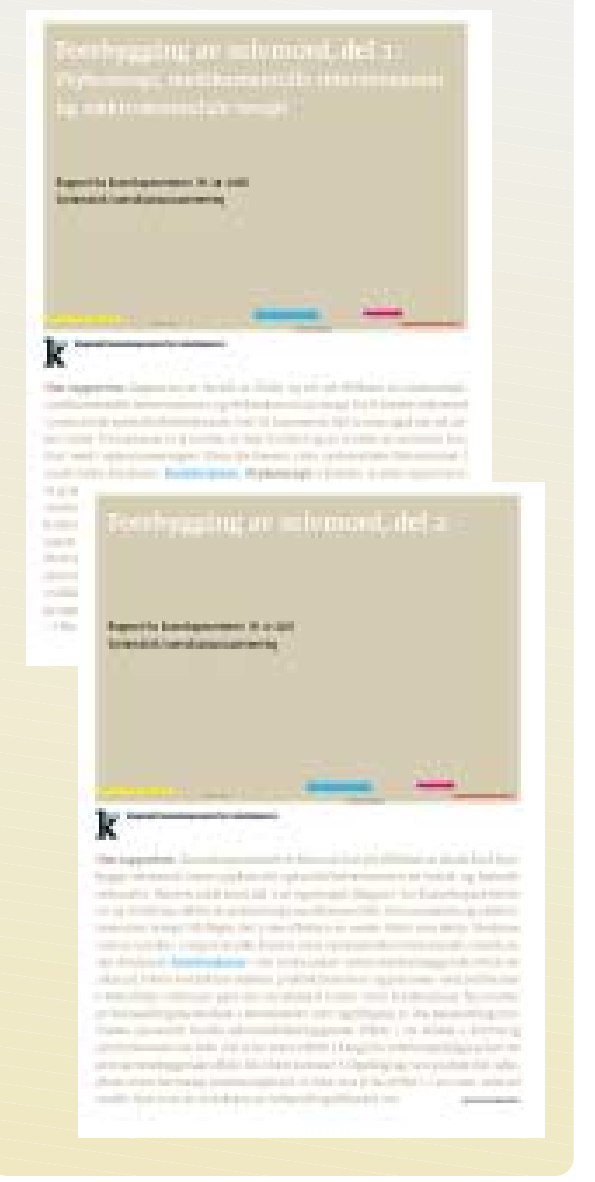

stilt i slutten av 2006, og begge rapportene er tilgjengelige i elektronisk format. På tross av det omfattende litteratursøket som lå til grunn for kunnskapsoppsummeringene, ble det identifisert relativt få gode studier, og samtidig var studienes relevans for behandling i psykisk helsevern generelt og for norske forhold spesielt variabel. Dette er grundig diskutert i begge del rapportene.

\section{Retningslinjene}

M ed kunnskapsoppsummeringene som utgangspunkt fortsatte den opprinnelige arbeidsgruppa arbeidet med selve retningslinjene. G ruppas arbeid har vært ledet av psykiater/fagsjef Ewa $\mathrm{N}$ ess fra U Ilevål universitetssykehus, og selve arbeidet med den skriftlige utformingen har undertegnede hatt hovedansvaret for. Begge var engasjert av $\mathrm{H}$ el sedirektoratet.

Både av hensyn til kunnskapsstatus på feltet (hva kan slås fast med støtte i forskning eller $\mathrm{i}$ konsensus blant fageksperter) og av hensyn til praktisk nytte for relevante brukere var det et behov for betydelige avgren sninger i omfanget av hva som kunne omtalesi retningslinjedokumentet. Selvmordsforebygging generelt er som kjent mangefasettert. Innen psykisk helsevern er det også vesentlig at man baserer seg på oppdatert kunnskap på andre områder slik som diagnostiske, relasjonelle og behandlingsspesifikke ferdigheter, juss, etikk mv. På tross av at de nevnte områdene er grunnleggende for effektiv selvmordsforebygging, ville en detaljert omtale av alle forhold raskt ta form av en omfattende lærebok, og det er ikke hensikten med en praktisk anvendelig retningslinje. I retningslinjene ble det særlig lagt vekt på følgende forhold:

- R etningslinjene skulle bygge på kunnskapsbaserte, ukontroversielle faglige standpunkter og ha som siktemål à heve den faglige standarden på feltet.

- Retningslinjene skulle være proaktive; dvs. fremme et forebyggen de perspektiv rettet mot alle pasienter i psykisk hel severn, og derved ikke bare rette seg mot identifiserte pasienter med suicidal problematikk, antatte høyrisikopasienter, -situasjoner eller -modaliteter (f.eks. akuttposter). 


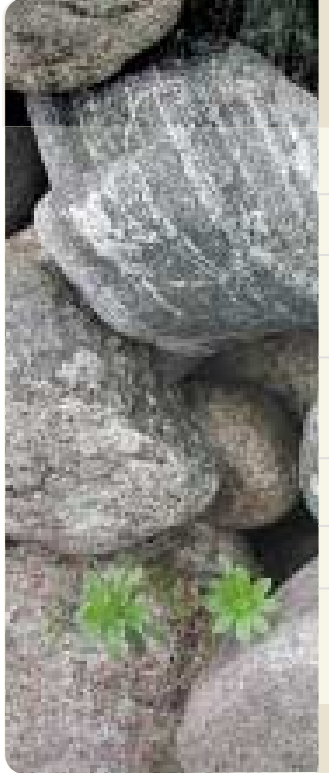

Tabell 1: Kliniske anbefalinger i Nasjonale retningslinjer for forebygging av selvmord i psykisk helsevern; 7 områder

1 Kartlegging og vurdering av selvmordsrisiko

2 Behandling

3 Forebygging av selvmord i døgnenheter i psykisk helsevern

4 Forebygging av selvmord etter utskriving fra døgnenheter i psykisk helsevern

5 Kronisk suicidalitet

6 Ivaretakelse av pårørende og etterlatte

$7 \quad$ Rapportering og oppfølging etter selvmord og alvorlige selvmordsforsøk

(Sosial-og helsedirektoratet, 2008)

- Retningslinjene skulle være kortfattete og mest mulig praktisk anvendelige.

- Retningslinjene skulle ikke inneholde umulige fordringer som stiller urimelige krav til tiltak eller ikke lar seg gjennomføre i helsetjenesten.

$M$ ed dette som utgangspunkt, og i noen grad påvirket av et lignende engelsk dokument ( $\mathrm{N}$ ational Institute for $\mathrm{M}$ ental $\mathrm{H}$ ealth, 2003), ble det skrevet utkast som ble videre diskutert frem til konsensus $\mathrm{i}$ arbeidsgruppa. A lle an befalingene ble graderte som hhv. sterke, moderate eller svake i henhold til "R etningslinje for retningslinjer" (Statens helsetilsyn, 2002). Kunnskapsstatus på feltet tilsa at de fleste anbefalingene fikk graderingen "svak". V åren 2007 mottok Sosial- og hel sedirektoratet arbeidsgruppas anbefalinger. I direktoratet gjennomgikk dokumentet en videre revisjon, med særlig vekt på juridiske aspekter. Direktoratet sen dte deretter en revidert versjon på en bred høring til hel seforetak, sentralt og lokale helsetilsyn, brukerorganisasjoner, profesjonsforeninger og andre. $\mathrm{M}$ an mottok en rekke høringssvar. U kontroversielle forslag til endringer ble så innarbeidet $\mathrm{i}$ dokumentet av Ewa $\mathrm{N}$ ess og undertegnede på vegne av arbeidsgruppa. Direktoratet har deretter videre bearbeidet dokumentet i tråd med politiske og juridiske føringer. Retningslinjene ble publisert i februar 2008 (Sosial- og hel sedirektoratet, 2008).
På dette området er det mye som tyder på at fagfeltet har sviktet, og området er en gjenganger i klagesaker ( $R ø n n e b e r g$ \& W al by, 2008). Retningslinjene går også langt i à an befale at selve vurderingen av sel vmordsfare bør gjøres av lege eller psykolog, i tråd med en konsensusanbefaling fra arbeidsgruppa. Bakgrunnen for denne anbefalingen er todelt; D els er kunnskap og ferdigheter i psykiatrisk diagnostikk en helt vesentlig del av en selvmordsrisikovurdering. $U$ ten en adekvat og integrert diagnostikk av pasientens psykiske problemer er det ikke mulig å gjøre en god risikovurdering. Dels er vurdering av selvmordsrisiko noe av det vanskeligste og mest alvorlige man gjør i psykisk helsevern og bør av den grunn forankres til den behandlingsansvarlige. Retningslinjene inneholder et eget avsnitt om selvmordsforebygging under opphold på døgnenheter og i den første tiden etter utskriving fra slike. Bakgrunnen for dette er at begge perioder er veldokumenterte høyrisikoperioder for suicidal atferd hvor spesifikke tiltak kan være påkrevd. Det er imidlertid viktig å få frem at retningslinjene gjelder for hele spesialisthelsetjenesten, ikke bare for sykehusavdelinger. Det er de polikliniske og ambulante enhetene som har størst pasientvolum, og hvor utfordringen med å etablere systematisk selvmordsforebyggen de arbeid kanskje er størst. Likeså gjelder retningslinjene på samme måte for spesial isthel setjenesten for barn og ungdom som for voksne. Det kan synes som om det kan være en særlig utfordring å øke det systematiske selvmordsforebyggen de arbeidet for barn og unge som er i behov av spesialisthelsetjenester.

A nbefalinger $\mathrm{i}$ forhold til arbeid med pårørende og etterlatte er beskrevet som et eget område. Dels gjelder dette anbefalinger for hvorledes pårørende bør trekkes inn, tilbys informasjon mv. i pågåen de behandlingsopplegg av pasienter med selvmordsproblematikk. Dels beskrives behovet for å ha klare prosedyrer for informasjon og videre oppføl gingstiltak etter at et selvmord har skjedd.

Det som kanskje er mest nytt av de 7 ulike områden e hvor direktoratet gir anbefalinger, er vektleggingen av forebyggende tiltak gjennom begrensning av tilgang til selvmordsmetoder som er 
beskrevet på s. 21-23. M an tar her utgangspunkt i den omfattende evidensen og sterke effekten slike tiltak har vist seg å kunne ha i den generelle befolkning, og søker på denne måten å øke fokus på dette området også i høyrisikosituasjoner. Særlig aktuelt er tiltak mot henging, som er den vanligste selvmordsmetoden på sengeposter.

I tråd med moderne kvalitetstenkning understrekes gjentatte ganger behovet for utarbeidelse av lokale skriftlige prosedyrer på flere områder. En rekke slike forslag til prosedyrer er lagt ved. Disse er ment som eksempler for å lette arbeidet med implementering i tjen estene, men har ikke i seg selv samme juridiske status som retningslinjene. Som kjent er det stor variasjon i hvorledes spesialisthelsetjenesten er organisert ulike steder i landet. Tankegangen er derfor at skriftlige prosedyrer må tilpasses lokale forhold for å være hensiktsmessige. Dette må imidlertid gjøres på en slik måte at de statlige anbefalingene gitt i retningslinjene og kravet til faglig forsvarlighet blir ivaretatt.

\section{Implementering og videre utfordringer}

H ensikten med retningslinjene er å redusere antall selvmord i psykisk helsevern i N orge. For å lykkes med dette er det viktig at de så raskt som mulig blir gjort kjent og implementert i det daglige kliniske arbeidet på ulike områder innen psykisk helsevern, og at de får en god forankring på ledel sesnivå. A rbeidsgruppa har forsøkt å lage et dokument som blir opplevd som nyttig og anvendelig i så måte. Samtidig kan det være rom for kvalitetsforbedring av retningslinjene. De bør derfor revideres om noen år. For å kunne gjøre dette på en god måte bør det utføres forskning både på implementeringen og effekter. Samtidig er både Seksjon for selvmordsforskning og -forebygging og RV T S'ene er i gang med å utarbeide ulike undervisningstiltak i kjølvannet av retningslinjene.

M ed nåværen de kunnskapsstatus er det ikke mulig å forebygge selvmord og andre beklagelige hendelser under behandling i psykisk helsevern. A rbeidet med suicidale pasienter og suicid under pågående behandling oppleves naturligvis som en stor følelsesmessig belastning for involvert helsepersonell. Det kan også gi tilsynsmessige og juridiske konsekvenser, noe vi må være forberedt på i økende omfang. Erfaringsmessig er høy kompetanse, god praksis og et proaktivt perspektiv av den største betydning for å motvirke slike konsekvenser. Samtidig er tilsyn og kontroll vesentlig for å sikre høy kvalitet i tjenestene, og retningslinjene gir også et godt grunnlag for ulike fagrevisjoner, tilsyn, klagesaksbehandling osv. Det er å håpe at retningslinjene oppleves som et nyttig bidrag til å høyne kvaliteten også her.

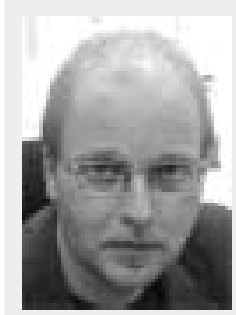

Fredrik $\mathbf{A}$. W alby er sjefpsykolog, Diakonhjemmet sykehus, Psykiatrisk avdeling, Vinderen - og forsker ved SSFF hvor han er involvert i en rekke forskningsprosjekter. H an var faglig sekretær for den nasjonale arbeidsgruppa som H elsedirektoratet nedsatte for å bistå med å utvikle nasjonale retningslinjer for forebygging av selvmord i psykisk helsevern.

\section{Referanser}

Bjørndal, A ., Flottorp, S., \& Klovning, A . (2000) M edisinsk kunnskapshåndtering. 0 slo: $G$ yldendal akademisk.

Cavanagh, J.-T. O., C arson, A ., Sharpe, M ., \& Lawrie, S. (2003). Psychological autopsy studies of suicide: a systematic review. Psychological Medicine, 33, 395-405.

H ansen, V., Jacobsen, B. K., \& A rnesen, E. (2001). C ause-specific mortality in psychiatric patients after deinstitutionalisation. British Journal of Psychiatry. 179:438-43.

H ytten, K. \& M ehlum, L. (1993). Selvmord blant innlagte pasienter i G austad sykehus 1954-91. Tidsskrift for Den norske lægeforening, 113, 19741977.

M ehlum, L., Dieserud, G ., Ekeberg, O ., G roholt, B., M ellesdal, L., W alby, F. A . et al. (2006). Forebygging av selvmord, del 1: Psykoterapi, medikamentelle intervensjoner og

elektrokonvulsiv terapi (Rapp.nr. 24). O sl o:

$\mathrm{N}$ asjonalt kunnskapssenter for hel setjenesten. H entet 20.5 .08 fra

http://www.nchs.no/site/0/Publikasjoner/534.cms M ehlum, L., Dieserud, G ., Ekeberg, O ., G roholt, B., M ellesdal, L., W alby, F. A . et al. (2007).

Forebygging av selvmord, del 2: (Rapp. nr. 4)

0 slo: $\mathrm{N}$ asjonalt kunnskapssenter for hel setjenesten. Hentet 20.5 .08 fra

http://www.nchs.no/site/0/Publikasjoner/678.cms
M ellesdal, L., M ehlum, L., \& Jørgensen, H. (2005). Suicidality in psychiatric emergency admissions -the SIPEA study. A prospective follow-up study. In XXIIIth C ongress of International A ssociation for Suicide Prevention. Durban

$\mathrm{N}$ ational Institute for M ental $\mathrm{H}$ ealth (2003)

Preventing suicide: A toolkit for mental health services. $H$ entet 20.5.08 fra http://213.121.207.229/ upload/SuicidePreventionTool kitweb.pdf

Q in, P. \& N ordentoft, M . (2005). Suicide risk in relation to psychiatric hospitalization: evidence based on longitudinal registers. A rchives of G eneral Psychiatry, 62, 427-432.

Rønneberg, U . \& W alby, F. A . (2008). Selvmord hos pasienter behandlet i psykisk helsevern. Tidsskrift for D en norske legeforening, 128, 180-183.

Ruud, T., G råve, R., \& H atling, T. (2006).

A kuttpsykiatrisk behandling i N orge - resultater fra en multisenterstudie (SINT EF-rapport A 310). Trondheim: SIN TEF H else.

Sackett, D. L., Rosenberg, M . L., G ray, J. A ., H aynes, R. B., \& Richardson, W. S. (1996). Evidence-based medicine: what it is and what it isn't. BM J, 312, 71-72.

Sosial- og helsedirektoratet. (2005). N asjonale retningslinjer og veiledere. 0 slo: Sosial- og helsedirektoratet. H entet 16.5.08 fra http://www.shdir.no/ kvalitetsforbedring/retningslinjer_veiledere/

Sosial- og helsedirektoratet. (2008). N asjonale retningslinjer for forebygging av selvmord $i$ psykiske helsevern. (IS-1511/2008). O slo: Sosialog helsedirektoratet.

Statens helsetilsyn. (2001). R utiner for registrering, behandling og oppfølging av pasienter innlagt i norske sykehus etter parasuicid. (IK2743/2001). O slo: Staten s helsetilsyn.

Statens helsetilsyn (2002). R etningslinjer for retningslinjer. (IK-2653). O slo: Statens helsetilsyn. Hentet 20.5.08 fra http://www.shdir.no/vp/ multimedia/archive/00011/IS-2653_11457a.pdf

W alby, F. A ., O degaard, E., \& M ehlum, L. (2005). $R$ isk Factors for completed suicide in psychiatric inpatients. In XXIIIth C ongress of International A ssociation for Suicide Prevention. Durban.

Walby, F. A ., O degaard, E., \& M ehlum, L. (2006) Psychiatric comorbidity may not predict suicide during and after hospitalization. A nested casecontrol study with blinded raters. Journal of A ffective Disorders, 92, 253-260.

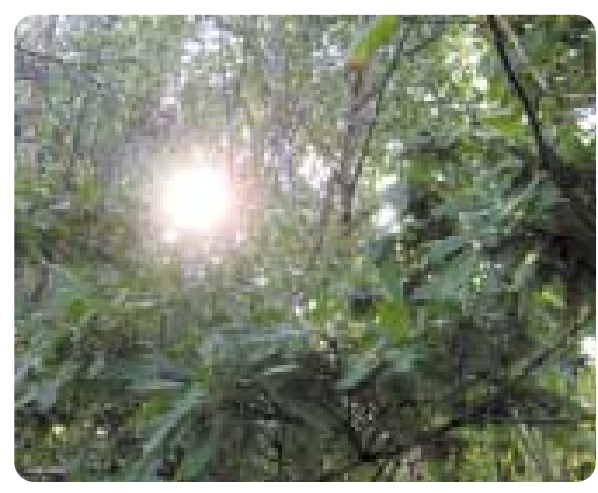

